\title{
EDITORIAL
}

\section{Cultural Issues in Research of Aggression. An Introduction to A Hot-Topic}

\author{
J. Martín Ramírez*
}

Head, UCM Research Group on Sociopsychobiology of Aggression, Psychobiology Department \& Institute for
Biofunctional Studies, Universidad Complutense Madrid, Pico de la Pala 6, 28792 Miraflores (Madrid), Spain

This special hot-topic issue arose mainly from a symposium dealing on cross-cultural issues in research of aggression, within the XXX CICA (International Colloquia on the Brain and Aggression) conference on "Conflict and aggression in a society in transition", held in Leányfalu (Hungary) in 2010. It wants to offer some sociopsychological approaches to several forms of interpersonal aggression and violence, from misconduct to killing, analyzing their levels of perception and acceptance in quite diverse cultures from Europe and South America to the Middle East and Southern Asia.

I am aware that the problem of aggression and violence is characterized by quite sensitive policy issues, which may lead to rather fierce ongoing debates. But even if some times politically motivated criticism on the topic still rears its ugly head, I think that a scientific approach to practical human problems that affect us all, like the ones we are dealing with, is a quite healthy criticism, indeed. This is the main reason, therefore, of offering the present issue.

In the first chapter Dr. Camilla Pagani introduces the topic of violence as the outcome of specific cognitive and emotional processes, such as threat, fear, hate, resentment, envy, and jealousy. She also considers its interconnections between individual level and macro-level (historical, juridical, economic, political, socio-cultural). With the humane perspective of a wise and compassionate woman, Dr. Pagani focuses especially on some western societies that have become destination of substantial immigration, such as the arrival of Northern Africans in Italy. In these cases violence violence may also be considered as a consequence of racism. Her analysis of youths of 9-18 years of age supports some interesting suggestions for educational interventions aiming to prevent, reduce, or eliminate violence in cross-cultural relations.

The next study, drawing on the own dissertation work of Dr. Violet Cheung, indeed contributes to research on acculturation and adolescent development in a nuanced way, providing a new approach in understanding the underlined mechanisms of the effects of Western acculturation on

*Address correspondence to this author at the UCM Research Group on Sociopsychobiology of Aggression, Psychobiology Department \& Institute for Biofunctional Studies, Universidad Complutense Madrid, Pico de la Pala 6, 28792 Miraflores (Madrid), Spain; Tel: 34918444 695;

Fax: 34913943 069; E-mail: mramirez@med.ucm.es
Chinese youth's delinquent behaviors, through the mediated variables, family obligations and autonomy timetable. The author provided excellent suggestions in intervention effort for solving misconduct problems, focusing on autonomy timetable and obligation discrepancy rather than on western influence per se. Dr. Cheung's study therefore is not only scientifically relevant, but also applicable to effective prevention strategies.

The article presented by Aref Abu-Rabia proficiently deals with a complex social and cultural problem: the practice of family honor killing among the Arabs in the Middle East, with particular attention to among Arab populations in Israel. It is an invaluable key to understanding Arab culture and will be of immeasurable value to scholars in this field. Dr. Abu-Rabia provides a lively portrait of Arab society, contributing significantly to the study of the Arab cultural values and customs. The research also analyzes what conflicts exist between custom and state law about family honor's killing, and how court systems relate to murders committed to save family honor.

The three last contributions present a cogent and helpful overview of how people of different age -children, adolescents, and young adults- perceive and justify several kinds of aggression in different cultures. Natalia Fares and her co-workers analyzed the justification of aggressive acts in Uruguayan children and adolescents of different age, sex and socioeconomic levels. They found that adolescents tended to justify both physical and verbal aggression more than children; and boys justified physical aggression more than girls, whereas no differences appeared in regard to verbal aggression.

The aim of Paz Toldos's study was to explore adolescents' perceptions of physical, verbal, and indirect aggression in hypothetical scenarios of aggression and to establish any sex differences in these perceptions. Results showed a significant interaction between the sex of the aggressor and the sex of the target: when the aggressor and the target were both males, the subjects perceived the aggressor as using physical and verbal aggression more often; and when the aggressor and the target were both females, subjects perceived the aggressor as using more verbal and indirect aggression. Dr. Toldos also rightly called attention to the fact that females perceived the use of indirect aggression more easily when the aggressor was a male and 
the target a female in a domestic context, and when the aggression took place between two adolescent females.

Finally, Ramirez's and Fung Lai Chu's research groups offer a cross-cultural approach to the degrees of approval for different aggressive acts in a number of instrumental and emotional situations by university students in Spain and Hong Kong. Their results confirmed findings of previous research in other cultures: patterns of moral approval of various kinds of aggressive acts are in a large part common to both cultures. In both populations, drastic forms of aggression were less accepted than mild and passive forms, more socially justified aggressive acts were clearly more accepted than others with no such justification, and instrumental-motivated aggression was higher justified than emotional-motivated aggression. Some differences in the level of acceptance according to the sex of the participants were also reported: although both sexes justified aggression in a higher degree for instrumentally motivated situations than for emotional ones, males showed a higher acceptance than females for instrumental situations, whereas women were more prone than men to a higher acceptance of acts and situations more related to emotion. There were also some minor culturally bound differences in these attitudes: aggression in emotional situations was less accepted by Spaniards, specially for the cases of punishment and lack of communication.

Summarizing, the results presented in this special issue may be a useful reference for academic research, and individuals interested in anthropology, sociology, psychology, criminology, education and social workers, police officers, politicians as well as policy makers, as far as it contributes to a deeper knowledge of the complex phenomenon of aggression across the human development.

C J. Martín Ramírez; Licensee Bentham Open.

This is an open access article licensed under the terms of the Creative Commons Attribution Non-Commercial License (http://creativecommons.org/licenses/_by-nc/3.0/) which permits unrestricted, non-commercial use, distribution and reproduction in any medium, provided the work is properly cited. 